\title{
DECODING CLIMATE MITIGATION MODELING STUDIES
}

\section{ROMAN HENNIG AND JUAN-CARLOS ALTAMIRANO}




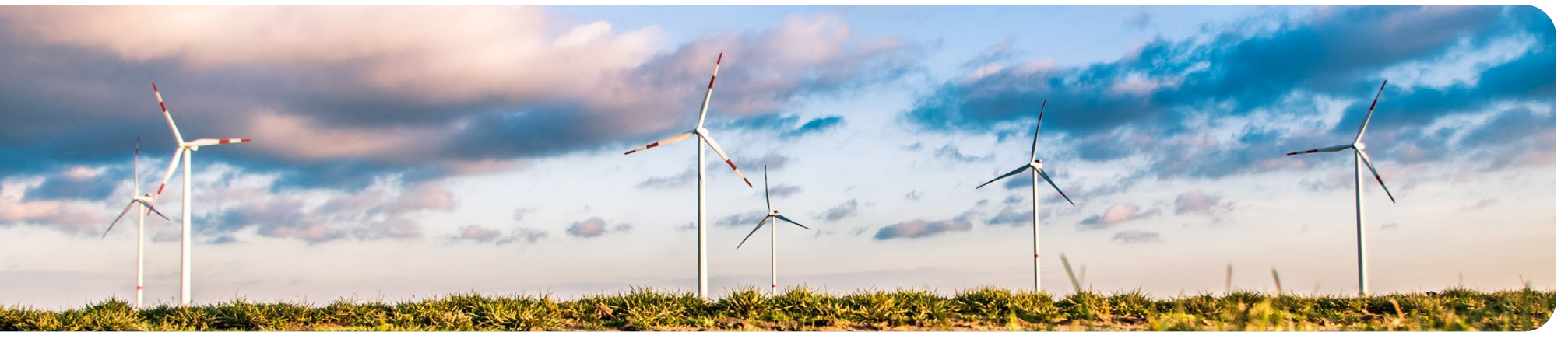

\section{CONTENTS}

$\begin{array}{ll}2 & \text { Highlights } \\ 2 & \text { Executive Summary } \\ 3 & \text { Introduction } \\ 4 & \text { Methodology and Approach } \\ 5 & \text { Why Modeling? } \\ 5 & \text { The Seven Dimensions of Modeling Studies } \\ & \text { for Climate Mitigation } \\ 17 & \text { Conclusions } \\ 17 & \text { AppendixA: Checklist for Climate Mitigation } \\ & \text { Modeling Studies (for Modelers) } \\ 18 & \text { Abbreviations } \\ 19 & \text { Endnotes } \\ 21 & \text { References } \\ 20 & \text { Acknowledgments } \\ 20 & \text { About the Authors } \\ & \end{array}$

\section{HIGHLIGHTS}

- Computer-based models are valuable tools for investigating scenarios for aligning near-term actions and policies with long-term goals.

- Nonexperts who contribute to climate mitigation decision-making need to be able to evaluate these models and recognize that there is no "best" model that answers all policy questions. We suggest that nonexperts assess seven dimensions-primary goals, the scope, the modeling framework, scenarios and data inputs, uncertainty, results, and process aspects-and determine if the studies are transparent about the assumptions and key inputs they use.

\section{EXECUTIVE SUMMARY}

\section{Computer-based models are valuable tools for} investigating scenarios for aligning near-term actions and policies with long-term goals. This issue brief provides guidance to nonexperts on what to look for in reading and evaluating studies that model climate mitigation. It describes seven dimensions to consider when reading modeling studies:

- Primary goals. Primary goals provide the general framing of a report and its objectives. Examples include achieving a given target for emissions levels, investigating the impacts of a carbon tax, or modeling specific policies and actions.

- Scope. The scope of modeling studies varies in terms of the time horizon covered, the geography considered (region, country, subnational entity), and the sectors and gases covered. 
- Modeling framework. A wide variety of models are available, each with a different level of complexity, strengths, and focus areas. For example, models can focus on energy, on emissions, or both. More complex models may include feedback loops and internal linkages between sectors. An explanation of the modeling framework should be provided and the workings of the model made transparent. Even in proprietary models, which cannot be made public, modelers can explain how the model works and what it does so that independent experts are able to understand how the study arrived at its results.

- Scenarios and data inputs. Studies provide reference scenarios that project the evolution of the system without new policies or interventions. They then compare that scenario with scenarios that include policies and interventions to investigate their impacts. Many assumptions and inputs go into scenarios, including population and gross domestic product projections, policies, rates of technological change, energy prices, trade, emissions factors, discount rates, and price elasticities. These assumptions affect the results. The integrity and trustworthiness of the data inputs are therefore of critical importance.

- Uncertainty. Modeling is inherently uncertain because the relationships assumed in the model are necessarily simplifications of reality, and the future developments of key inputs of the scenarios are not known. Modeling studies can address uncertainty by providing a range of results based on different input assumptions and/or using a variety of model specifications.

- Results. The main results of climate mitigation studies typically concern the emissions or energy use of the modeled system under different scenarios. For policy and planning, detailed results on the underlying energy and electricity system are also important; in some cases, it can be helpful to provide more detailed results on other sectors, such as transportation, buildings, industry, agriculture, and waste. When considering results for the buildings sector, for instance, it is important to distinguish between direct emissions (from burning gas for heating, for example) and indirect emissions (from electricity consumption). Some studies highlight the financial implications of different scenarios (costs and required investments). Modeling studies may also consider the cobenefits of reducing emissions, such as reduced air pollution, and the equity impacts of the required transitions, such as lost jobs in declining industries.

- Process aspects. Process aspects-including who wrote the report, who commissioned it, and what the author's motivation was-can affect how the findings of a study should be interpreted. Another important consideration is whether and to what degree stakeholders were involved in the creation and framing of scenarios. Stakeholder involvement can help increase ownership and uptake of the results, bring in relevant knowledge from different stakeholders, and build capacity in participating organizations. However, heavy involvement of political stakeholders can result in watered-down results because governments may present findings in a positive light or minimize commitments. Finally, there should be an indication of whether a lack of data, time, or other resources prevented a thorough treatment of the area studied.

An overarching element permeating these dimensions is transparency. Studies should identify their focus, inputs, assumptions, and sensitivities to key parameters (among others). Technical information and supplementary data should be provided in a technical appendix or online.

\section{Transparency on data inputs is necessary for} building trust in a study. Data inputs and the choice of parameters and other assumptions drive the results of modeling exercises. It is therefore important to verify that the data are reliable and can be traced to their sources.

\section{INTRODUCTION}

The need for clear and strong action to avoid disastrous consequences from climate change is more than evident. Countries are taking a range of different actions to reduce greenhouse gas (GHG) emissions covering both the short and long terms. For instance, the Paris Agreement invites all Parties to submit their GHG emissions reduction objectives through nationally determined contributions (NDCs) and to update or submit new NDCs by 2020 to raise the ambition of national climate mitigation efforts. 
The use of computer models helps to address these challenges and to analyze quantitatively the climate policy and actions needed for that. Many groups have developed these computer models to explore potential scenarios.

These scenarios can identify a range of options for reaching long-term climate mitigation targets and indicate what kinds of investments, actions, and policies can enable this transition. Table 1 presents the definitions of the main concepts (model, scenario, and prediction) used in this issue brief.

The ability to look at a wide range of objectives and assumptions makes computer models ideal tools for assisting with short-, medium-, and long-term planning. Yet because no standard framing for modeling studies of this type exists, it can be difficult for decision-makers to make sense of the plethora of studies. The objectives investigated vary widely across studies-and even the same given set of objectives are investigated in many ways. The assumptions modelers make about socioeconomic development, policies, technologies, and economic indicators can also differ widely.

These challenges are the motivation for this issue brief. The intended target audience includes policy decisionmakers as well as researchers at nongovernmental organizations (NGOs), think tanks, consulting groups, and universities who seek to understand the results of modeling to make informed decisions to address climate change.

Readers interested in the results of modeling studies may want to

- clearly define their own goals about what insights they wish to glean from modeling;

- look for studies whose goals and scope align with their interests and use this issue brief as guidance for points to look for; and

- use this issue brief as a guide for what to look for when reviewing a study or asking modelers to commission one.

\section{DEFINITIONS OF TERMS USED}

$\begin{array}{ll}\text { Term } & \text { Definition } \\ \text { Model } & \text { Models are analytical representations (often } \\ & \text { constructed as spreadsheets or computer } \\ \text { programs) of human activity sectors, such as } \\ \text { the electricity system, transport, buildings, } \\ \text { and industry, and their greenhouse gas emis- } \\ \text { sions. They may include the resource needs and } \\ \text { interactions of different sectors with each other } \\ \text { and environmental systems, such as the climate } \\ \text { system. They can be used to investigate the effects } \\ \text { of climate mitigation policies and actions and, in } \\ \text { some cases, development issues such as energy } \\ \text { access and economic prosperity. Models can vary } \\ \text { widely in their scope, computational approach, and } \\ \text { purpose. They define various scenarios based on } \\ \text { input assumptions. } \\ \text { A scenario is "a plausible description of how the } \\ \text { future may develop based on a coherent and } \\ \text { internally consistent set of assumptions about key } \\ \text { driving forces (for example, the rate of technolog- } \\ \text { ical change, prices) and relationships."a Modeling } \\ \text { studies often produce reference (or baseline) } \\ \text { scenarios, which are developed to forecast what } \\ \text { would happen in the absence of further interven- } \\ \text { tions. They provide a basis against which policy } \\ \text { and intervention scenarios are compared. }\end{array}$

Prediction/ A prediction (or forecast) is an estimate of the forecast future state of the system under investigation. Scenarios are meant to showcase the impacts of different policy choices and interventions rather than serve as predictions of the actual evolution of a system. The main difference is that a scenario is one of the many alternative states of the future; thus, it may contain information from a projection together with framing information.

Source: a. IPCC 2013.compilation

\section{METHODOLOGY AND APPROACH}

This issue brief draws on modeling studies in four countries- Colombia, India, Indonesia, and South Africawhich are part of the Tracking and Strengthening Climate Action (TASCA) project of the World Resources Institute (WRI). ${ }^{1}$ Across these countries, 20 studies met the following criteria: they are directed to policymakers, they focus on national analyses (though some also included subnational analysis), and they include emissions pathways from human activities. 
The studies surveyed included academic literature, think tank publications, government reports, and several international studies, including studies by the U.S. Energy Information Administration (EIA 2018), the Potsdam Institute for Climate Impact Research (Schmid and Knopf 2012), and the International Panel on Climate Change (IPCC 2013).

Review of these studies led to the identification of seven dimensions that are critical for understanding modeling studies. This issue brief explains what they are and why they are important, and it provides examples from some of the studies identified. The set of dimensions is neither exhaustive nor definite; it could have been grouped differently, but it reflects many common features of modeling reports. This list could be further refined by additional stakeholder and expert consultations.

The issue brief also draws on modeling results from a module of the Climate Watch Pathways, a database of models and scenarios intended to provide users with modeling study results to identify opportunities for delivering on a country's climate goals. 2

\section{WHY MODELING?}

Policymakers concerned with planning over different time horizons need a way to provide an idea of future policy outcomes, formulate targets for the desired end state, and identify transition pathways to achieve those end states. They need to know whether their policies and actions will deliver their expected reductions and how they can achieve their mitigation targets.

Computer-based models are ideally suited to tackle these challenges. They provide insights that are anchored in data, reveal the trade-offs and synergies between different policy and investment options, and provide decisionmakers with a quick overview of their likely impacts.

Another benefit of creating scenarios is that the process of doing so can help stakeholders forge a unified vision and agree on a harmonized set of base-year assumptions that can be used by different stakeholders and agencies as a common framework.

We suggest that nonexperts assess seven dimensions-primary goals, the scope, the modeling framework, scenarios and data inputs, uncertainty, results, and process aspectsand recognize along them whether the studies are transparent about the assumptions and key inputs they use.

\section{THE SEVEN DIMENSIONS OF MODELING STUDIES FOR CLIMATE MITIGATION}

Modeling studies for climate mitigation can be compared across seven dimensions:

1. Primary goals

2. Scope

3. Model framework

4. Scenarios and data inputs

5. Uncertainty

6. Results

7. Process aspects

Not all studies include comprehensive information on all of these dimensions. Some focus on one or more dimensions and treat others only in passing or indirectly. If a study does not include information on a dimension, it should provide an explanation of why it was omitted. In the appendix, we suggest a list of elements that, at minimum, modelers should report in their analyses.

The most useful studies are transparent about what is included within these dimensions. It should be possible for an independent expert to look at a study and determine what the underlying assumptions are and what drives the results. Input assumptions and an explanation of how the model works should be available-presented in a technical appendix or by making the source code of the model openly available and documenting it well. Even if the model is proprietary and the source code cannot be made available, modelers can increase transparency by providing details on how the model works.

\section{Primary Goals and the Framing of the Study}

When reading a report, first look for its main goals. They should be clearly identified because they are the guidepost for assessing and understanding the report. They also influence many other important aspects of the report, such as the scope, the modeling framework, the choice of scenarios, and the process.

The goals of modeling studies can vary widely. This issue brief considers only studies concerned with climate mitigation aspects. Many modeling studies have been developed on related topics, such as adaptation and readiness for climate change and its impact on poverty, income, and energy access (Dittrich et al. 2016; Balint et al. 2017). 
Even among studies considering only climate mitigation, the range of goals is wide (Box 1). Goals can be economy wide (such as achieving a certain level of emissions reduction for the economy) or sectoral (such as achieving a specific level of penetration of renewable energy in the electricity sector or a given number of electric vehicles in the transport sector). The type of goal considered will affect the choice of model. Many studies also consider related impacts, such as spillover effects across sectors, financial implications, cobenefits, and impacts related to equity and distributional aspects.

\section{EXAMPLES OF THE PRIMARY GOALS OF MODELING STUDIES}

Studies set various primary goals:

- A study of Colombia analyzes the effects of implementing a price on carbon (e.g., carbon taxes) and emissions reductions on gross domestic product, consumption, and the energy sector. ${ }^{a}$

- A study of Indonesia assesses the technical feasibility of a pathway to the deep decarbonization of the energy system. ${ }^{\text {b }}$

- A study of South Africa explores deep decarbonization pathways that focus on development challenges, such as ways to decrease unemployment, $^{\mathrm{c}}$

Sources: a. Calderón et al. 2016; b. Siagian et al. 2015; c. Altieri et al. 2015.

\section{Scope of the Report}

Another important distinction between studies concerns their scope-the economic sectors, time frame, geography, and important output variables, such as different types of GHGs. The scope depends on the purpose of the study (see Table 2). For long-term decarbonization planning, for example, it is important to check that the report provides results through at least 2050. For complete decarbonization of the economy, it is necessary to look at all major emitting sectors and GHGs, not just carbon dioxide $\left(\mathrm{CO}_{2}\right)$ or the electricity sector.

The main considerations for scope include the following:

- Sectoral coverage. Does the report consider all economic sectors or only sectors like electricity or energy? Does it include land use, forestry, and agriculture?
- Time frame. What is the time horizon of the analysis? What is the start year? At which time step are results available (monthly, 1 year, 5 years, 10 years)?

- Geographical coverage. Does the study focus on a single country, or is it part of a multicountry study? Does it include subnational or regional detail? Does it include trade and other types of exchange with the rest of the world?

- GHGs and other pollutants. Which GHGs are included? Are emissions measured in $\mathrm{CO}_{2}$ equivalent ( $\mathrm{CO}_{2} \mathrm{e}$ ) or $\mathrm{CO}_{2}$ only? (If the findings are reported in $\mathrm{CO}_{2}$ only, they probably reflect only $\mathrm{CO}_{2}$; if they are reported in $\mathrm{CO}_{2} \mathrm{e}$, they probably include at least methane, which, in most cases, accounts for the largest share of non- $\mathrm{CO}_{2}$ emissions. Are other gases covered by the Kyoto Protocol-nitrous oxide, hydrofluorocarbons, perfluorocarbons, and sulfur hexafluoride-modeled? Does the report consider other emissions and climate forcers, such as particulate matter, ozone, and black carbon? Does the report distinguish between direct emissions and indirect emissions (for example, emissions associated with electricity use by buildings)?

- Costs, savings, and prices. Does the model include information on the costs of policies and investments, such as the savings achieved under different policies? Does it include projections of fuel prices?

- Other impacts. Does the report address other nonemissions impacts, such as jobs created, energy access, and other environmental impacts (such as on soil or water)?

\section{The Modeling Framework and Justification of Model Choice}

Models can be classified under two sets of characteristics (Rich et al. 2014): ${ }^{3}$

1. Top-down, bottom-up, and hybrid models. Topdown models project overall economic output and emissions intensity based on projections of intersectoral relationships, considering the impact on GDP, consumption, and investment. They include the Organisation for Economic Co-operation and Development's ENV-Linkages model, the Model for the Assessment of Greenhouse Gas Induced Climate Change (MAGICC), and the Global Change Assessment Model (GCAM). 


\section{EXAMPLES OF REPORT SCOPE}

\begin{tabular}{|c|c|c|c|c|}
\hline Country/Study & Sectors & Gases & Time Horizon & $\begin{array}{l}\text { Geographic } \\
\text { Coverage }\end{array}$ \\
\hline India & $\begin{array}{l}\text { Economic sectors, with } \\
\text { detailed electricity model } \\
\text { and detail on buildings and } \\
\text { transport }\end{array}$ & $\begin{array}{l}\mathrm{CO}_{2} \text { emissions from energy } \\
\text { sector }\end{array}$ & $\begin{array}{l}2050 \text { for detailed analysis, } \\
2100 \text { for long-term implica- } \\
\text { tions analysis; base year is } \\
2015\end{array}$ & $\begin{array}{l}\text { National; modeling } \\
\text { includes interactions } \\
\text { with rest of world } \\
\text { because the model is } \\
\text { global, with } 32 \text { world } \\
\text { regions }\end{array}$ \\
\hline Indonesiab & $\begin{array}{l}\text { Building, transportation, } \\
\text { industry, and electricity }\end{array}$ & $\mathrm{CO}_{2}$ only & $\begin{array}{l}2050 \text {, with } 10 \text {-year time steps } \\
\text { from the base year }(2010)\end{array}$ & $\begin{array}{l}\text { National; interactions } \\
\text { with rest of world are not } \\
\text { explicitly discussed }\end{array}$ \\
\hline South Africa ${ }^{c}$ & $\begin{array}{l}\text { Detailed sectoral and } \\
\text { subsectoral breakdown; } \\
\text { industry sector disaggre- } \\
\text { gated to metals, minerals, } \\
\text { chemicals production, } \\
\text { mining, and buildings; } \\
\text { transport sector disag- } \\
\text { gregated by road, rail, and } \\
\text { aviation }\end{array}$ & Aggregated $\left(\mathrm{CO}_{2} \mathrm{e}\right)$ & $\begin{array}{l}2050 \text {, in } 10 \text {-year time steps for } \\
\text { most results; base year is } 2010\end{array}$ & $\begin{array}{l}\text { National; international } \\
\text { trade is not explicitly } \\
\text { included }\end{array}$ \\
\hline South Africad & $\begin{array}{l}\text { All major economic sectors, } \\
\text { with subsectoral detail } \\
\text { for industry (nonferrous } \\
\text { metals, iron and steel, } \\
\text { nonmetallic minerals, } \\
\text { chemicals, pulp and paper, } \\
\text { other, food and beverage, } \\
\text { and mining), buildings } \\
\text { (commercial and resi- } \\
\text { dential), and transport } \\
\text { (personal and freight) }\end{array}$ & $\mathrm{CO}_{2}$ only & $\begin{array}{l}\text { National; international trade is } \\
\text { not explicitly included }\end{array}$ & $\begin{array}{l}\text { National; international } \\
\text { trade is used to produce } \\
\text { model results and is } \\
\text { explicitly mentioned as } \\
\text { a driver in the economic } \\
\text { structure scenario but } \\
\text { is not included in the } \\
\text { presentation of results }\end{array}$ \\
\hline
\end{tabular}

Notes: $\mathrm{CO}_{2}=$ carbon dioxide; $\mathrm{CO}_{2} \mathrm{e}=$ carbon dioxide equivalent.

Sources; a. Chaturvedi et al. 2018; b. Siagian et al. 2015; c. DEA 2014; d. Altieri et al. 2015.

Bottom-up models project energy use by type and sector, based on disaggregated data on specific technologies. Bottom-up accounting models work from exogenous assumptions regarding structural and policy developments in each sector. Bottom-up optimization models reflect a least-cost allocation of technology choices or maximize energy production. Bottom-up models include the Long-Range Energy Alternatives Planning (LEAP) system, the Model for Analysis of Energy Demand (MAED), Market and Allocation (MARKAL), the Model for Long-Term Energy Demand Evaluation (MEDEE), and the
Prospective Outlook on Long-term Energy Systems (POLES).

Hybrid models combine the two approaches. They include the Energy Policy Simulator (EPS), MARKALMacro, and National Energy Modeling System (NEMS).

2. Jurisdiction-specific versus generic models. Jurisdiction-driven models-such as the NEMS model for the United States, the Energy-Economy Environment Model for Canada (E3MC), and the Dynamic Dispatch Model (DDM) for the United 
Kingdom-are developed for specific countries or other jurisdictions to reflect their unique circumstances. They are tailored to capture the complexities of the jurisdiction's economic and energy systems.

Generic models, which are designed to meet the needs of multiple users, can be customized to fit a user's specific needs. For users with limited capacity, generic models can provide a more detailed focus than jurisdiction-driven models for sectors like electricity generation, cement, and iron and steel. For other sectors with characteristics that vary widely across countries (such as transport), generic models are not typically available. Therefore, jurisdiction-driven or customized generic models may be required.

One important aspect that is common to all model types is the level of detail at which systems are represented. Models run along a spectrum from highly detailed to highly aggregated. They can include underlying details for one sector but consider other sectors in an aggregated fashion. For example, electricity models often model only the future electricity mix. They may be highly detailed in their representation of the electric power supply and grid but take aggregate demand from other sectors as fixed and not responding to changes in prices. Power system models may offer detailed seasonal daily load curves (i.e., the daily variation in consumer energy demand) and dispatch of different energy carriers rather than just an average fixed output. Models for the building sector may provide outputs such as floor space estimations for urban and rural residential and commercial buildings and building energy end use for cooling, heating, appliances, and lighting. An even more detailed representation might include the location, energy use, age, and ownership of specific buildings in a city. Transport models can assess the automobile fleet by freight/passenger and engine type and include a list of every licensed car and its make, age, and fuel efficiency. Corresponding highly aggregated quantities for these variables would be the total energy demand and emissions of buildings and transport.

Many different modeling frameworks can be chosen to investigate a given set of primary goals. It is important to understand why the modeling framework was used and why it is suited to investigate the stated objectives of the study. It is also important to acknowledge potential weaknesses and limitations. For complete transparency, a detailed explanation of the modeling framework should be available in a technical appendix or online. Table 3 provides examples of modeling frameworks and how they were used to address the primary goals of studies.

\section{Scenarios and Data Inputs}

A scenario is an internally consistent set of assumptions and relationships. Ideally, it will describe both the numbers that reflect the assumptions, goals, and results of a modeling exercise and a qualitative narrative, which describes the ideas and story lines for the future behind those numbers and assumptions. For instance, Figure 1 shows a reference case and a conditional NDC scenario (Flores et al. 2019). The reference case scenario presents Mexico's current emissions trajectory with no interference from additional policies and abatement actions. The conditional NDC scenario shows the emissions trajectory to achieve Mexico's 2030 conditional NDC target of 36 percent GHG abatement versus the reference case. Moreover, the conditional NDC scenario includes (among other policies) a US\$50 per metric ton of $\mathrm{CO}_{2} \mathrm{e}$ carbon tax, increased distributed solar photovoltaic generation capacity, improved forest management actions, and more stringent light-duty and heavy-duty vehicle fuel economy standards.

Scenarios are a central concept in modeling studies. They showcase different sets of assumptions and results and measure the impact of different choices of inputs and policies on the attainment of goals. Comparing different scenarios reveals the trade-offs associated with different choices.

Scenario analysis is often confused with forecasting. Many scenarios are not meant to be a precise description of the future state of a system. Rather, they are meant to highlight the implications of different actions and assumptions. Reference (or baseline) scenarios are often developed as a counterfactual of the likely evolution of the system in the absence of further actions. They are created to reveal the impact of policies and actions. The takeaways of modeling studies are often the differences between the reference scenario and the policy scenarios. 


\section{EXAMPLES OF ADDRESSING OBJECTIVES IN MODELING STUDIES}

\begin{tabular}{|c|c|c|c|}
\hline Country/Study & Models Used & Primary Objectives & Additional Objectives \\
\hline Colombia ${ }^{a}$ & $\begin{array}{l}\text { Global Change Assessment Model } \\
\text { (GCAM) } \\
\text { - TIMES Integrated Assessment } \\
\text { Model of the Energy Research } \\
\text { Centre of the Netherlands (TIAM- } \\
\text { ECN) } \\
\text { - Phoenix model } \\
\text { - MEG4C model }\end{array}$ & $\begin{array}{l}\text { Model the substitutions required } \\
\text { between different energy sources } \\
\text { and changes in the electricity system }\end{array}$ & $\begin{array}{l}\text { Estimate the impacts of an economy- } \\
\text { wide carbon tax }\end{array}$ \\
\hline Indiab & $\begin{array}{l}\text { GCAM Integrated Assessment } \\
\text { Model } \\
\text { - Indian Institute of Management } \\
\text { Ahmedabad version }\end{array}$ & $\begin{array}{l}\text { Investigate the impacts of different } \\
\text { price trajectories for energy fuels } \\
\text { and the costs of integrating variable } \\
\text { renewable energy in the end uses of } \\
\text { energy (e.g., buildings and transport) }\end{array}$ & $\begin{array}{l}\text { Assess energy access issues for } \\
\text { urban/rural households }\end{array}$ \\
\hline Indiac & $\begin{array}{l}\text { Market and Allocation (MARKAL) } \\
\text { model }\end{array}$ & $\begin{array}{l}\text { Assess least-cost options for energy } \\
\text { systems }\end{array}$ & $\begin{array}{l}\text { Analyze the impacts of new tech- } \\
\text { nologies and priorities for research, } \\
\text { development, and investment }\end{array}$ \\
\hline South Africad & $\begin{array}{l}\text { South African TIMES Electricity } \\
\text { (SATIM-E) supply model } \\
\text { Energy Extended South African } \\
\text { General Equilibrium (e-SAGE) }\end{array}$ & $\begin{array}{l}\text { Analyze power sector and electricity } \\
\text { demand, production, and prices }\end{array}$ & $n / a$ \\
\hline
\end{tabular}

Note: $\mathrm{n} / \mathrm{a}=$ not applicable.

Sources; a. Calderón et al. 2016; b. Chaturvedi et al. 2018; c. Das et al. 2013; d. Altieri et al. 2015.

\section{DESCRIPTION OF SCENARIOS FOR MEXICO TO ATTAIN NDC OBJECTIVES}

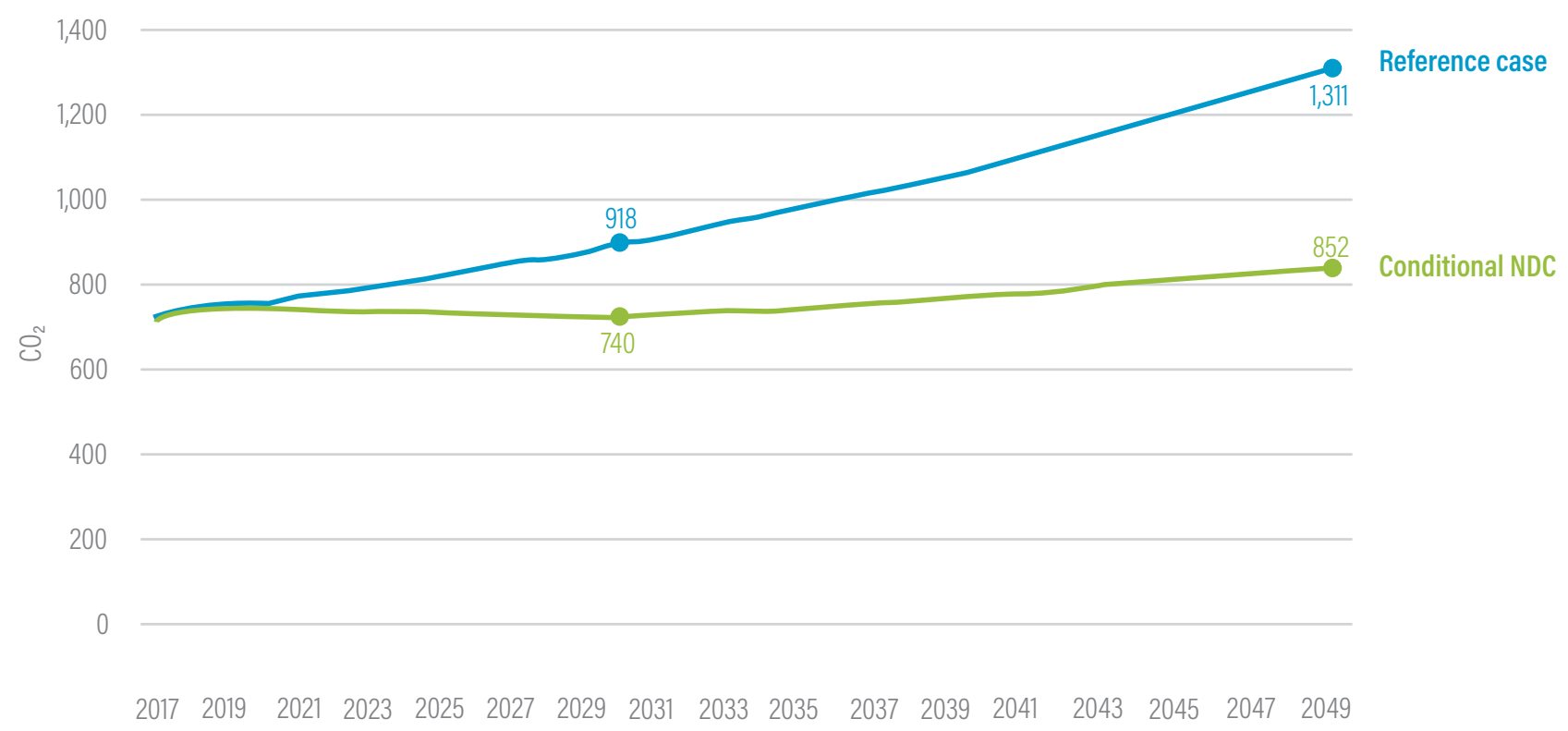

Note: $\mathrm{NDC}=$ nationally determined contribution; $\mathrm{tCO}_{2} \mathrm{e}=$ metric tons of carbon dioxide.

Source: Flores et al. 2019. 


\section{Reference Scenario Assumptions}

Reference scenarios provide a counterfactual of what is most likely to happen in the absence of any further intervention. These scenarios are often also called business-asusual or baseline scenarios.

Many assumptions go into the construction of the reference scenario. It is important to be aware of them-especially when comparing two studies based on different models-because the choice of assumptions can have a greater effect on the outcome than the choice of modeling methodology. Ideally, each assumption in a model should be justified by adequate backing studies or expert opinions. Table 4 provides examples of some important assumptions.

\section{Policies and Interventions Used in Scenarios}

Scenarios are often constructed around goals-for decarbonization of the economy, inclusive growth, or sustainable development, for example. Policies and interventions affect the achievement of these goals.

\section{KEY MODELING ASSUMPTIONS}

$\begin{array}{ll}\text { Variable } & \text { Explanation } \\ \text { Population } & \text { Changes in population drive the need for new buildings, } \\ & \text { transportation, industrial activity, and food production, } \\ & \text { among others. }\end{array}$

Gross domestic product (GDP) and economic growth

Policies and actions

Existing policies and actions may be explicitly represented
Aggregate economic activity, quantified as GDP, depends on population, productivity, and factors of production such as labor, land, and industrial machinery. When economic activity is an exogenously provided parameter, it is a driver of model results. For some models, it can also be an output.
Questions to Ask about the Assumption

- Are the population projections clearly stated? What source was used to generate them (externally supplied or within the model)?

- Do the projections include subnational details?

- Are they broken down by working age, urban/rural, educational attainment, or income level?

- Are the GDP projections clearly stated?

- What source was used to generate them (externally supplied or within the model)?

- Is GDP provided at the subnational and sectoral level?

- If the model provides GDP estimates, how were these projected?

- Are growth rate assumptions disaggregated by sector? in the model. Sometimes studies explicitly include only policies and actions implemented before a certain cutoff year. Studies should clarify what assumptions are used for policies and how they are translated into the model framework.
- Which policies and actions were included in the baseline scenario?

- Are any policies excluded from the report? If so, explain why they were excluded?

- What is the policy cutoff year (the last year for which existing policies were considered)?

- How are the impacts of existing policies estimated and represented in the model?

- Does the model provide information on the price and price variation over time of technologies such as wind, solar, and hydropower; biomass; electric vehicles; batteries; and CCS?

- Is the information disaggregated by region?

- Are there explicit assumptions about build rates (in gigawatts or carbon mitigated per year)? and build rates of new technologies (such as renewable energy sources and carbon capture and storage [CCS]) may be included in the model. They are useful for assessing whether enough of these resources can be deployed in time or enough space is available for multiple competing land uses (for example, for bioenergy and food crops).
Technological learning rates
The learning curve usually leads technology prices to taper over time.
- What learning rates are assumed for technologies such as solar, wind, batteries, and CCS? 


\section{KEY MODELING ASSUMPTIONS (CONTINUED)}

\section{Variable}

Energy and fuel

prices

\section{Trade}

A country's consumption depends partly on international trade.

Prices for fuels such as oil, gas, and coal determine many model although in many cases they are computed as an output by the can lead to a shift to more renewable energy.$$
\text { A country's consumption depends partly on international trade. }
$$

Questions to Ask about the Assumption results. Sometimes electricity prices are also supplied exogenously, model. High fuel prices can lead to faster adoption of energy efficiency measures; high prices of carbon-intensive energy carriers

Emissions factors Emissions factors indicate the extent to which emissions are embedded in each unit of emissions-producing activity or emissions per unit of fuel. The choice of emissions factors affects a study's results.
Discount rate

Price elasticities and elasticities of substitution

A social discount rate is typically used to reduce ("discount") the value of costs and benefits occurring in the future. It reflects the fact that people tend to value the future less than the present. The value of this parameter can be highly subjective and controversial. It can have strong effects on the results of models and the implications drawn from them. This choice can affect whether to make an investment. In addition to the social discount rate, which affects the analysis of costs and benefits for society, there are also private and corporate discount rates for private citizens and companies.

The higher an elasticity, the stronger the response to price change. For example, a high gasoline price elasticity means that consumers will use much less gasoline if the price increases. They might switch to other fuels (such as biofuels), change the activity that requires gasoline (use public transport instead of a car), or cease engaging in an activity altogether. Price elasticities of substitution characterize the change in consumption of alternatives to a good when the price of that good changes (e.g., switching from a coalbased power supply to natural gas or renewable energy sources). Tuning parameters like these can give modelers power over the study's outcomes. This information should therefore be transparent and the assumptions justified by empirical studies.

Exchange rates and Exchange rates between currencies can fluctuate significantly. year of currency value In order to compare studies from different times, it is important to account for these differences.
- What are current and future prices of oil, gas, coal, electricity, and any other fuels used?

- Are they expressed in a clear currency, and are they in real or current terms?

- Are fuel prices responsive to demand for fuels?

Is trade included in the analysis?

- For which commodities and with which other regions is it modeled?

- Are electricity imports and exports included?

- What emissions factors are assumed for different electricity-generation technologies, industries, transport, and agriculture?

- What is the source of the emissions factors?

- Are the factors country specific or regional/global?

- What are the assumptions about social, household, and corporate discount rates?

- What are price elasticities for commodities such as gasoline, oil, natural gas, and coal?

- Does the model provide information about whether consumers switch fuels based on prices? If so, at which price does the switch occur?

- Do consumers choose more efficient technologies (for cars and appliances, for example) in response to fuel and electricity price increases?

- Do consumers consume less in response to fuel and electricity prices (driving less or using less electricity, for example)?

- What year is used for currency values?

- What exchange rates between currencies are assumed for trade?

- Are there any changes in land-use practices?

- Do weather conditions affect model parameters (e.g., heating and cooling degree days)? 
It is important to understand how policies have been translated to the modeling framework, how their impacts are measured, and how they interact with one another. Sequencing can influence the effects of different policies. For instance, is smart grid development before or after the renewable energy plans are designed? This may influence the final costs of the energy produced. The reader should check that the report clearly explains key items for scenarios, including the following:

- Constraints on the value of an indicator. Models can constrain certain relevant parameters (e.g., overall level of emissions, a particular percentage of renewable energy in the energy mix) for attaining a specific target such as reaching net-zero emissions in 2050 or reaching NDC goals by 2030 . Some models can automatically allocate emissions reductions based on economic (e.g., cost efficiency) or other criteria (e.g., social acceptance). Scenarios based on costs or acceptance criteria can be helpful in showcasing possible pathways to reach the specified targets. They may not directly show the instruments and policies required to achieve these targets, however. Models can demonstrate what a given narrative implies for a country or what a given constraint entails in terms of sectoral transformations. They can showcase pathways that are feasible and cost-effective. Implementing these solutions in the real world requires targeted policies and actions that may be outside the scope of the modeling study. When encountering a constraintbased scenario, readers are encouraged to think about what it would take to implement the required transformation.

- Specific policies and actions. Policies and actions can be modeled explicitly. Policies such as vehicle fuel efficiency standards, building codes, and industrial efficiency standards or policy packages, such as the U.S. Clean Power Plan, can be represented in many ways. They can be constraints on the values of particular indicators (e.g., the percentage of electric vehicles in the total vehicle fleet), command and control (for example, fuel efficiency of cars or efficiency of electric appliances), or market based, taking the form of price incentives, taxes, or support for research and development, which reduces the costs of new technologies.
- Scenario sets. Scenarios often bundle policies and actions, especially when the number of scenarios would become too large if every possible policy combination were modeled separately. Some models solve this problem through interfaces that allow users to explore the impact of different policy packages for themselves, ${ }^{4}$ but this solution comes at the expense of simplifying the model enough for public users to be able to use them.

- Changes of input parameters based on the scenario narrative. Sometimes authors of a report develop a narrative for change that alters the assumptions for specific input parameters to the model (such as those presented in Table 4 above). Table 5 compares baseline scenarios with policy scenarios in various modeling efforts.

\section{Uncertainty}

Uncertainty is inherent to modeling. It can be divided into two types (Heal and Millner 2014). The first type is uncertainty about the development of key input indicators. Many inputs in modeling exercises have strong impacts on the results (examples include population, the prices of energy carriers, and technological learning rates). The future level of these inputs is inherently uncertain. For building trust in the results of a modeling study, it is critical to use reputable input sources and be transparent about the choices of inputs and assumptions. The second type is uncertainty about the model itself. Uncertainty also stems from the structure, parameters, and assumed relationships in the model and the way policy implementation is translated to the modeling framework. Models are always a simplified representation of real-world systems. Thus, even if future inputs were known with certainty, the effects would likely be different than the model assumes. This type of uncertainty is known as parametric and structural uncertainty.

Uncertainty can be accounted for in modeling studies in several ways (Box 2). Uncertainty regarding input indicators can be addressed by including a sensitivity analysis of the key inputs for the scenarios modeled (including different assumptions for single key scenario inputs and seeing how the results change) and conducting Monte Carlo analysis on a range of inputs. In this technique, modelers specify the ranges in which key inputs will likely fall. A random number generator then draws a value out of these ranges for each input, and the model is run with the selected input values. This process is repeated many times, which results in a distribution of possible outcomes. 


\section{SCENARIOS INCLUDED IN REPORTS ON MITIGATING CLIMATE CHANGE}

\begin{tabular}{|c|c|c|}
\hline \multirow[t]{2}{*}{ Country/Report } & \multicolumn{2}{|r|}{ Scenario } \\
\hline & Baseline & With Policies/Interventions \\
\hline Colombia ${ }^{a}$ & $\begin{array}{l}\text { The business-as-usual scenario includes } \\
\text { climate and energy policies passed before } \\
2010 .\end{array}$ & $\begin{array}{l}\text { The high } \mathrm{CO}_{2} \text { price scenario considers a carbon tax of US } \$ 50 / \\
\mathrm{tCO} \mathrm{O}_{2} \text { e in } 2020 \text { that increases by } 4 \% \text { a year to reach } \$ 162 / \mathrm{tCO} \mathrm{C}_{2} \mathrm{e} \text { in } \\
2050 \text {. } \\
\text { The } 50 \% \text { abatement scenario reduces greenhouse gas emissions } \\
\text { (excluding land-use changes) by } 12.5 \% \text { by } 2020 \text {, linearly increasing } \\
\text { to a } 50 \% \text { reduction by } 2050 \text {. } \\
\text { The } 50 \% \text { fossil fuel and industrial abatement scenario reduces } \\
\text { fossil fuel and industrial } \mathrm{CO} \mathrm{C}_{2} \text { emissions by } 12.5 \% \text { by } 2020 \text {, linearly } \\
\text { increasing to a } 50 \% \text { reduction by } 2050 \text {. }\end{array}$ \\
\hline Indiab & $\begin{array}{l}\text { The reference scenario assumes medium } \\
\text { economic growth, medium cost trajectory for } \\
\text { solar and wind, low cost trajectory for coal } \\
\text { and nuclear, and high cost trajectory for gas. }\end{array}$ & $\begin{array}{l}\text { The paper generates } 216 \text { scenarios resulting from combina- } \\
\text { tions of different cost pathways for coal, gas, nuclear, solar, and } \\
\text { wind-based energy generation and } 3 \text { different economic growth } \\
\text { pathways. }\end{array}$ \\
\hline Indiac & $\begin{array}{l}\text { The reference energy scenario considers only } \\
\text { current trends and policies as of the publica- } \\
\text { tion date (2013). }\end{array}$ & $\begin{array}{l}\text { The renewable energy scenario assumes that fossil fuels and } \\
\text { nuclear-based technologies are phased out and replaced, when } \\
\text { feasible, with renewable options. }\end{array}$ \\
\hline Indiad & $\begin{array}{l}\text { The business-as-usual scenario considers } \\
\text { that policy strategies ongoing at the time are } \\
\text { implemented. }\end{array}$ & $\begin{array}{l}\text { The policy scenario assumes stronger policy actions with sustain- } \\
\text { ability objectives (energy security, inclusivity, and cleaner air) in } \\
\text { the power, industry, transport, agriculture, and buildings sectors. }\end{array}$ \\
\hline Indonesia ${ }^{e}$ & $n / a$ & $\begin{array}{l}\text { The economic structure scenario assumes a transition to a low- } \\
\text { carbon economy accompanied by an adjustment in world prices } \\
\text { for some products and import/export elasticities of domestic } \\
\text { producers, meant to simulate an increase in trade openness. } \\
\text { The high-skills scenario assumes that the transition is combined } \\
\text { with an increase in the supply of highly skilled labor, which drives } \\
\text { an increase in employment and demand in the model. } \\
\text { Both scenarios are subject to a carbon constraint of } 14 \text { gigatonnes } \\
\text { of cumulative emissions until 2050. }\end{array}$ \\
\hline South Africa ${ }^{\dagger}$ & $n / a$ & $\begin{array}{l}\text { The policy scenario assumes stronger policy actions with sustain- } \\
\text { ability objectives (energy security, inclusivity, and cleaner air) in } \\
\text { the power, industry, transport, agriculture, and buildings sectors. }\end{array}$ \\
\hline South Africag & $\begin{array}{l}\text { The "without-measures" scenario assumes } \\
\text { economic growth without any carbon } \\
\text { constraint. }\end{array}$ & $\begin{array}{l}\text { - The "with-existing-measures" scenario includes policies and inter- } \\
\text { ventions as specified by South Africa's current development plan. } \\
\text { - The "with-additional-measures" scenario assumes different miti- } \\
\text { gation scenarios in order of increasing ambition. }\end{array}$ \\
\hline United Statesh & $\begin{array}{l}\text { The reference case projection assumes } \\
\text { improvement in the further development } \\
\text { of known technologies and economic and }\end{array}$ & $\begin{array}{l}\text { The side cases assume variation in parameters, such as high and } \\
\text { low oil prices, high and low advances in oil and gas technology, } \\
\text { and high and low economic growth, among others. }\end{array}$ \\
\hline
\end{tabular}

demographic tendencies following leading assumptions from forecasts. The scenario leaves out the potential impacts of unenacted legislation, regulations, and standards. 
Model uncertainty can be mitigated by examining a range of models, as often done in the model comparison exercises of the integrated assessment modeling community. ${ }^{5}$ Another (rarely used) way to account for this type of uncertainty would be to run a model with different parameters or structural specifications.

Looking at results under a range of inputs and modeling assumptions can make the implications for policy more robust. If a policy portfolio performs well under a wide range of assumptions, it may be preferred over one that performs very well under certain assumptions but poorly under others.

\section{EXAMPLES OF UNCERTAINTY ANALYSES USED IN MODELING STUDIES}

\section{Studies deal with uncertainty in various ways:}

- A study of Colombia compares four models to reduce structural uncertainties, ${ }^{\mathrm{a}}$

- A study of India combines different cost pathways for coal, gas, nuclear, solar, and wind-based energy generation and three economic growth pathways, leading to a total of 216 scenarios. ${ }^{b}$

- A study of South Africa conducts a sensitivity analysis of results for different economic growth rates. ${ }^{c}$

Sources: a. Calderón et al. 2016; b. Chaturvedi et al. 2018; c. DEA 2014.

\section{Results}

This section considers the results of modeling exercises. It distinguishes between results related to emissions, energy and end-use sectors, financial implications, cobenefits, and equity-related impacts. Some results may fit into several categories.

Results on emissions, energy, and end-use sectors are often the most directly related to the primary objectives of climate mitigation modeling studies. Emissions trajectories for reference and policy scenarios show how far the decarbonization of the economy progresses in the modeled scenarios and if targets such as those of the NDCs or long-term strategies are reached. Emissions can also be broken down by economic sector, end use, fuel source, and GHG or pollutant. Information on the energy system can include the capacity and generation breakdown of the electricity system, capacity additions and retirements, and energy use by resource (coal, gas, oil, biofuels, and variable renewables) and by sector (fuel switches in the transportation sector and the profile and level of energy consumption in the industrial sector). Models may be able to show detailed results for end-use sectors, such as travel demand by vehicle type, the composition of the vehicle fleet, and industrial and agricultural outputs.

\section{Financial and Economic Indicators}

Costs and returns on investments play a crucial role in planning. Firms need to understand the investments needed for a low-carbon economy and to be aware of any potential risks. Policymakers need to be aware of the potential costs or revenues of policies and regulations for the government. They may find it desirable to align financial incentives for businesses with low-carbon and development goals. The Paris Agreement explicitly recognizes the need to shift investments in order to make financial flows consistent with long-term temperature goals. Investments in sustainable infrastructure and business ideas are drivers of the transition to a low-carbon economy (Global Commission on the Economy and Climate 2018).

Financial and economic indicators include investments, cash flow, costs, and savings (see Box 3). Model results may indicate the following:

- The size and timing of investments required in the energy system, infrastructure, the building stock, and energy efficiency

- Cash flows for governments, consumers, and firms (including government revenues from a carbon tax or costs for subsidies, consumer costs for increased energy prices, and gains or losses to firms from policies)

- Cost assumptions of different energy and electricity sources or integrating variable renewable energy into the electricity grid

- Savings associated with climate-friendly policies such as from efficiency increases or better transport management; models may also include savings from avoided damages from climate change mitigation. 
EXAMPLES OF FINANCIAL AND ECONOMIC INFORMATION INCLUDED IN MODELING STUDIES

\author{
Studies include financial information in their modeling in \\ various ways:
}

- A study of India provides detailed analysis of the costs to the government and energy producers to include variable renewable energy sources in the energy mix under different policy assumptions and analyzes the implications of different cost trajectories for all major energy carriers. ${ }^{\text {a }}$

- Another study of India analyzes the required investments in energy supply, the value of energy imports under different scenarios, the social value of carbon, and the associated revenues from avoided carbon dioxide emissions. ${ }^{b}$

- A study of Indonesia identifies the investments required for renewable energy, new vehicle types, biorefineries, and fossil power plants. ${ }^{\mathrm{C}}$

- A study of South Africa includes a multicriteria analysis that incorporates socioeconomic indicators, including jobs and gross value added. ${ }^{\mathrm{d}}$ It also considers environmental impacts not related to greenhouse gases and examines the costs and economic impacts for each of 172 identified mitigation measures. It provides marginal abatement cost curves for each mitigation measure (based on capital investment costs as well as operation and maintenance costs and energy cost savings) and estimates aggregate impacts on sectoral gross domestic product.

Sources: a. Chaturvedi et al. 2018; b. Shuklaa et al. 2015; c. Siagian et al. 2015; d. DEA 2014.

\section{Cobenefits}

Climate experts are increasingly recognizing that to reach climate targets, it is not enough to just focus on GHG emissions. Instead, it is useful to frame decarbonization from a sustainable development perspective as well as to reflect improvements in quality of life and to assemble broad stakeholder coalitions around these notions (Araya 2018). Models therefore investigate cobenefits and reduction in potential unintended consequences on segments of the population (Box 4).

Examples of cobenefits include health benefits associated with a reduction in air pollution because of a shift away from fossil fuels, increases in energy access and improvements in service, reductions in water use (in waterstressed areas) for thermal power plants by switching to wind- and solar-powered electricity, and net job creation in new technology sectors.

\section{EXAMPLES OF INCORPORATING COBENEFITS INTO MODELING STUDIES}

Studies incorporate cobenefits in the following ways:

- A study of India looks at income, jobs, electricity access, electricity cost, water, and land impacts. ${ }^{a}$

- Another study of India analyzes the reduced import dependency on fossil energy carriers and the energy savings associated with increased energy efficiency. ${ }^{b}$

- Another study of India incorporates energy access, energy security, water access, air and water quality, sanitation, housing access, food security, livelihoods, health quality, and biodiversity. ${ }^{\mathrm{C}}$

- A study of Indonesia examines savings related to energy efficiency improvements and diversification toward a more service-oriented economy. ${ }^{d}$

- A study of South Africa models cobenefits as part of its multicri-

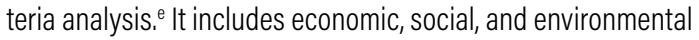
impacts not related to greenhouse gases; changes in gross value added; job creation, the proportion of low-skilled jobs, and nonmonetary social impact; and water, solid and hazardous waste, and land impacts.

Sources: a. Chaturvedi et al. 2018; b. Das et al. 2013; c. Byravan et al. 2017; d. Siagian et al. 2015; e. DEA 2014.

\section{Equity-Related Impacts and Impacts on Vulnerable Populations}

Poor and vulnerable segments of the population generally bear the brunt of the pollution burden because wealthier residents can afford to move out of polluted areas. Modeling studies may be helpful to assess changes such as energy transitions and how these are likely to affect some populations positively and others negatively. These changes should be measured to evaluate the equity impacts of policies.

The transition to cleaner energy may leave some segments of the population worse off, particularly by reducing the number of jobs in coal mining, oil and gas drilling, and fossil fuel-based power plants. There is a need to design measures to protect these vulnerable populations. Actions are necessary to ensure a "just transition" (Newell and Mulvaney 2013; Healy and Barry 2017; Heffron and McCauley 2018). 
Models can highlight impacts like these and show ways to mitigate the burden of the transition on vulnerable populations. Readers of a modeling report should look for the following:

- Does the report examine the impacts on jobs in affected sectors (e.g., coal mining and coal power plants)?

- Does the report identify groups that would be worse off in the proposed pathways? Are they vulnerable segments of the population?

- Does the report identify alternative employment opportunities, retraining opportunities, or other ways to offset negative impacts?

\section{Process Aspects}

The overall process from the initial discussions and design can shape the framing and outcomes of a study. Elements like contextual information and stakeholder involvement are key to understanding the overall framing of a study.

\section{Contextual Information}

To understand the context within which a report was produced-and identify potential biases-it is helpful to identify the following:

- Who wrote the study?

- Who commissioned it?

- What was the mandate and motivation for producing the report?

- Was the report peer-reviewed?

For example, a report produced by an environmental NGO is likely to be framed very differently from one produced by a major oil producer. As a result, the outcomes may differ substantially. It can be helpful to consult studies from a variety of backgrounds.

Peer review strengthens the academic integrity of a study. The peer-review process takes time, however. For this reason, many think tanks and research organizations publish studies outside of peer-reviewed academic journals. Readers should consider how transparent these studies are about their inputs and modeling assumptions.

\section{The Stakeholder Involvement Process}

Involving stakeholders in the development of scenarios can strengthen studies in several ways (Box 5). This can ensure that the views of all affected parties are reflected in the objectives of a modeling exercise. Doing so increases co-ownership and acceptance of the results and their implications. For scenarios related to climate change mitigation, for example, codevelopment can lead to better mainstreaming of climate plans into the plans of sectoral ministries, better alignment with incentives for the private sector, and awareness-building measures for civil society. It can also improve the underlying input data assumptions and help check results for reasonableness and feasibility. Heavy involvement of political actors can result in watered-down results, however, if it leads to efforts to present the government in a positive light or to try to minimize commitments. Readers should recognize this potential in assessing government-mandated studies or studies from institutes closely aligned with the government.

Codevelopment of scenarios with relevant actors can also help build capacity. Involving political stakeholders or their staffs in scenario creation and the vetting of results helps them understand and act on relevant results. Involving stakeholders also allows modelers to draw on the experience and knowledge of stakeholders in areas in which they themselves are not experts. It also increases the chance that a scenario includes the views of groups that may be disadvantaged by actions or policies.

\section{EXAMPLES OF STAKEHOLDER INVOLVEMENT IN MODELING STUDIES \\ Studies involve stakeholders in various ways:}

- A study of Germany drew on dialogue with stakeholders from the transport and electricity sectors to determine what conditions would define the scenarios for the German energy transition. ${ }^{a}$ Stakeholders evaluated the feasibility and social acceptance implications of the scenarios.

- For its study of South Africa, the Department of Environmental Affairs established a Technical Working Group on Mitigation that included a range of stakeholders from government departments, businesses, civil society, and academic institutions. ${ }^{\mathrm{b}}$ The purpose of the working group was to assess mitigation potential and best-available mitigation options in all economic sectors and identify the economic, environmental, and social impacts of the proposed mitigation options. The stakeholders also coordinated and aligned mitigation work at the sectoral and national levels. 


\section{CONCLUSIONS}

Modeling is a powerful tool for investigating potential pathways for achieving a given set of objectives. It can have a strong impact on the formation of plans to deliver on NDCs. Reviewing a study while keeping in mind the dimensions presented in this issue brief can help readers assess the study's relevance for a given objective and clarify its main policy conclusions. This framework may also provide policymakers and other stakeholders commissioning modeling studies with a template for what to look for from the exercise.

This issue brief helps stakeholders understand the modeling studies available, explains the parts of a study, and shows how different assumptions may shape the results. Future work could extend the discussion to other important issues, such as the short-term policy implications of long-term policy planning.

We have identified the following seven dimensions:

- Primary goals. These goals provide the general framing of a report and its objectives (e.g., how to achieve a target for emissions levels or investigating the impacts of a carbon tax).

- Scope. It is important to check the terms of the time horizon covered, the geography considered (region, country, subnational entity), and the sectors and gases covered.

- Modeling framework. A wide variety of models are available, each with a different level of complexity, strengths, and focus areas. An explanation of the modeling framework should be provided-and the workings of the model made transparent-so that readers are able to understand how the study arrived at its results.

- Scenarios and data inputs. These project the evolution of the system with and without new policies or interventions. The assumptions and inputs that go into scenarios affect the results. The integrity and trustworthiness of the data inputs is therefore of critical importance.

- Uncertainty. Modeling studies can address uncertainty by providing a range of results based on different input assumptions and/or using a variety of model specifications.

- Results. These typically concern the emissions or energy use of the modeled system under different scenarios. For policy and planning, detailed results on the underlying energy and electricity system are also important; in some cases, it can be helpful to provide more detailed results on other sectors, such as transportation, buildings, industry, agriculture, and waste. Modeling studies may also consider the cobenefits of reducing emissions, such as reduced air pollution, and the equity impacts of the required transitions, such as lost jobs in declining industries.

- Process aspects. These include who wrote the report, who commissioned it, and what the author's motivation was; these aspects can affect how the findings of a study should be interpreted. Another important consideration is whether and to what degree stakeholders were involved in the creation and framing of scenarios.

\section{APPENDIX A: CHECKLIST FOR CLIMATE MITIGATION MODELING STUDIES (FOR MODELERS)}

Ideally, modelers should follow this checklist when conducting a study:

1. Outline the research questions and objectives

Describe the problem and research motivation

Describe if the study examines only climate mitigation indicators or other related indicators (e.g., gross domestic/state product, employment, measures of cobenefits)

2. Describe the modeling scope

Describe modeling scope criteria, including sectoral coverage, time frame, geographical coverage, environmental and climate metrics, and economic indicators

3. Identify the modeling framework

Explain the strengths and weaknesses of the modeling framework used, emphasizing the research objectives and key assumptions

4. Explain the modeling scenarios

Describe the reference scenario(s) and justify key assumptions 
Explain how the modeling scenarios link to relevant policies, goals, and stakeholder inputs

Provide clear narratives and descriptions for policies and actions considered under each scenario

5. Gather data inputs

Identify the data required to run the model

Convert the gathered data into a format appropriate for sharing (if the model is publicly available)

Explain the inherent anomalies and biases in the data sets used

6. Run the model and analyze the results

Use the initial results to highlight sources of uncertainty and limitations

Generate and compare the results under a range of modeling assumptions

Include a sensitivity analysis of key inputs

7. Communicate the results and modeling limitations

Present the results in formats that best suit research questions, objectives, and audience

Highlight key modeling limitations and explain how these limitations affect the interpretation of the results or could affect the credibility of the study

8. Explain the process aspects

Provide information about the modeling team, research sponsor, and involvement of other stakeholders

Explain peer-review and validation processes

Consider and implement other measures to increase modeling transparency

\section{ABBREVIATIONS}

CCS

$\mathrm{CO} 2$

$\mathrm{CO} 2 \mathrm{e}$

EPS

e-SAGE

GCAM

GDP

GHG

LEAP

MAED

MAGICC

MARKAL

MEDEE

NDC

NEMS

NGO

POLES

SATIM-E

TASCA

TIAM-ECN

WRI carbon capture and storage

carbon dioxide

carbon dioxide equivalent

Energy Policy Simulator

Energy Extended South African General Equilibrium

Global Change Assessment Model

gross domestic product

greenhouse gas

Long-Range Energy Alternatives Planning

Model for Analysis of Energy Demand

Model for the Assessment of Greenhouse Gas Induced Climate Change

Market and Allocation

Model for Long-Term Energy

Demand Evaluation

nationally determined contribution

National Energy Modeling System

nongovernmental organization

Prospective Outlook on Long-term Energy Systems

South African TIMES Electricity

Tracking and Strengthening Climate Action

TIMES Integrated Assessment Model of the Energy Research Centre of the Netherlands

World Resources Institute 


\section{ENDNOTES}

1. This study is designed to inform WRI's TASCA initiative, which supports national governments with tools and resources to track progress toward meeting their national climate commitments and strengthen climate action.

2. For further information, see the Climate Watch Pathways database, https://www.climatewatchdata.org/pathways.

3. For more information on models, see the studies by Deutsche Gesellschaft für Internationale Zusammenarbeit (GIZ 2017), which looks at simulation models for mitigation measures related to NDC implementation; Novikova et al. (2016), which discusses the monitoring of nationallevel mitigation actions; Pye and Bataille (2016), which focuses on the modeling frameworks used for the Deep Decarbonization Pathways Project; and Kriegler et al. (2015), which presents a detailed characterization of integrated assessment models.

4. Examples include the 2050 calculator (https://www.gov.uk/guidance/ international-outreach-work-of-the-2050-calculator) and the Energy Policy Simulator (https://www.energypolicy.solutions/).

5. See, for instance, the AR5 Scenario Database (https://tntcat.iiasa.ac.at/ AR5DB/) or the modeling and scenario comparison at the Energy Modeling Forum (https://emf.stanford.edu/).

\section{REFERENCES}

Altieri, K., H. Trollip, T. Caetano, A. Hughes, B. Merven, and H. Winkler. 2015. Pathways to Deep Decarbonization in South Africa. New York: Sustainable Development Solutions Network; Paris: Institute for Sustainable Development and International Relations. http://deepdecarbonization.org/ wp-content/uploads/2015/09/DDPP_ZAF.pdf.

Araya, M. 2018. Increasing the Ownership of Long-Term Climate Plans by Integrating Sustainable Development Goals. Washington, DC: World Resources Institute. https://files.wri.org/expert-perspective-araya.pdf.

Balint, T., F. Lamperti, A. Mandel, M. Napoletano, A. Roventini, and A. Sapio. 2017. "Complexity and the Economics of Climate Change: A Survey and a Look Forward." Ecological Economics 138 (August): 252-65. https://doi. org/10.1016/j.ecolecon.2017.03.032.

Byravan, S., S.B. Mohd, S. Ali, M.R. Ananthakumar, N. Goyal, A. Kanudia, P.V. Ramamurthi, S. Srinivasan, and A.L. Paladugul. 2017, "Quality of Life for All: A Sustainable Development Framework for India's Climate Policy Reduces Greenhouse Gas Emissions." Energy for Sustainable Development 39 (August): 48-58. https://doi.org/10.1016/j.esd.2017.04.003.

Calderón, S., A.C. Alvarez, A.M. Loboguerrero, S. Arango, K. Calvin, T. Kober, K. Daenzer, and K. Fisher-Vanden. 2016. "Achieving CO 2 Reductions in Colombia: Effects of Carbon Taxes and Abatement Targets." Energy Economics 56 (May): 575-86. https://doi.org/10.1016/j.eneco.2015.05.010.

Chaturvedi, V., P.N. Koti, and A.R. Chordia. 2018. Sustainable Development, Uncertainties, and India's Climate Policy. New Delhi: Council on Energy, Environment and Water. https://www.ceew.in/sites/default/files/CEEW_ Sustainable_Development_Uncertainties_India_Climate_Policy_30Apr18.pdf.
Das, S., A. Kumar, I. Mohan, A. Arora, A.K. Jindal, and L. Mann. 2013. The Energy Report-India: 100\% Renewable Energy by 2050. Mumbai: The Energy Resources Institute. https://www.teriin.org/sites/default/files/completed_ es/ES2012MS01.pdf.

DEA (Department of Environmental Affairs). 2014. South Africa's Greenhouse Gas Mitigation Potential Analysis, Pretoria: DEA, Republic of South Africa. http://www.caia.co.za/wp-content/uploads/2016/05/mitigationreport.pdf.

Dittrich, R., A. Wreford, and D. Moran. 2016. "A Survey of Decision-Making Approaches for Climate Change Adaptation: Are Robust Methods the Way Forward?" Ecological Economics 122 (February): 79-89, https://doi. org/10.1016/j.ecolecon.2015.12.006.

EIA (U.S. Energy Information Administration). 2018. Annual Energy Outlook 2018 with Projections to 2050. Washington, DC: EIA. https://www.eia.gov/ outlooks/aeo/pdf/AE02018.pdf.

Flores, A., J.-C. Altamirano, F. Olea, A. Zafra, and J. Rissman. 2019. Choosing the Right Path: Low-Cost Policy Options for Enhancing Mexico's Climate Goals while Achieving Long-Term Social Benefits. Washington, DC: World Resources Institute. https://files.wri.org/s3fs-public/choosing-right-path_0. pdf.

GIZ (Deutsche Gesellschaft für Internationale Zusammenarbeit). 2017. Methodological Approach towards the Assessment of Simulation Models Suited for the Economic Evaluation of Mitigation Measures to Facilitate NDC Implementation. Bonn: GIZ. https://www.transparency-partnership. net/system/files/document/simmodel-methodological-approach\%28web\%29_20180214.pdf.

Global Commission on the Economy and Climate. 2018. Unlocking the Inclusive Growth Story of the 21st Century: Accelerating Climate Action in Urgent Times. Washington, DC: Global Commission on the Economy and Climate. https://newclimateeconomy.report/2018/.

Heal, G., and A. Millner. 2014. "Uncertainty and Decision Making in Climate Change Economics." Review of Environmental Economics and Policy 8 (1): 120-37. https://doi.org/10.1093/reep/ret023.

Healy, N., and J. Barry. 2017. "Politicizing Energy Justice and Energy System Transitions: Fossil Fuel Divestment and a 'Just Transition."' Energy Policy 108 (September): 451-59. https://doi.org/10.1016/j.enpol.2017.06.014.

Heffron, R.J., and D. McCauley. 2018. "What Is the 'Just Transition'?" Geoforum 88 (January): 74-77. https://doi.org/10.1016/j.geoforum.2017.11.016.

IPCC (Intergovernmental Panel on Climate Change). 2013. "Annex III: Glossary." In Climate Change 2013: The Physical Science Basis. Contribution of Working Group I to the Fifth Assessment Report of the IPCC, edited by T.F. Stocker, D. Qin, G.-K. Plattner, M. Tignor, S.K. Allen, J. Boschung, A. Nauels, Y. Xia, V. Bex, and P.M. Midgley. Cambridge and New York: Cambridge University Press.

Kriegler, E., N. Petermann, V. Krey, V.J. Schwanitz, G. Luderer, S. Ashina, V. Bosetti, J. Eom, A. Kitous, A. Méjean, L. Paroussos, F. Sanoi, H. Turton, C. Wilson, and D.P. Van Vuuren. 2015. "Diagnostic Indicators for Integrated Assessment Models of Climate Policy." Technological Forecasting and Social Change 90 (January): 45-61. https://doi.org/10.1016/j.techfore.2013.09.020. 
Newell, $P_{1}$, and D. Mulvaney. 2013. "The Political Economy of the 'Just Transition."' Geographical Journa/ 179 (2): 132-40. https://doi.org/10.1111/ geoj.12008.

Novikova, V., J. Fuessler, M. Molnar, and A.0. Abdel-Aziz. 2016. Compendium on Greenhouse Gas Baselines and Monitoring National-Level Mitigation Actions. New York: United Nations Framework Convention on Climate Change. https://unfccc.int/files/national_reports/non-annex_i_natcom/ cge/application/pdf/final-compendium-mitigation-actions.pdf.

Pye, S, and C. Bataille. 2016. "Improving Deep Decarbonization Modelling Capacity for Developed and Developing Country Contexts." Climate Policy 16 (S1): S27-46. https://doi.org/10.1080/14693062.2016.1173004.

Rich, D., P. Bhatia, J. Finnegan, K. Levin, and A. Mitra. 2014. Greenhouse Gas Protocol: Policy and Action Standard-an Accounting and Reporting Standard for Estimating the Greenhouse Gas Effects of Policies and Actions. Washington, DC: World Resources Institute. https://files.wri.org/s3fs-public/ Policy_and_Action_Standard.pdf.

Schmid, E., and B. Knopf. 2012. "Ambitious Mitigation Scenarios for Germany: A Participatory Approach." Energy Policy 51 (December): 662-72. https://doi. org/10.1016/j.enpol.2012.09.007.

Shuklaa, P.R., S. Dhar, M. Pathak, D. Mahedevia, and A. Garg. 2015. Pathways to Deep Decarbonization in India. New York: Sustainable Development Solutions Network; Paris: Institute for Sustainable Development and International Relations. http://deepdecarbonization.org/wp-content/ uploads/2015/09/DDPP_IND.pdf.

Siagian, U.W.R., R.G. Dewi, R. Boer, l. Hendrawan, B.B. Yuwono, and G.E. Ginting. 2015. Pathways to Deep Decarbonization in Indonesia. New York: Sustainable Development Solutions Network; Paris: Institute for Sustainable Development and International Relations. http://deepdecarbonization.org/ wp-content/uploads/2015/11/DDPP_IDN.pdf.

\section{ACKNOWLEDGMENTS}

We are pleased to acknowledge our institutional strategic partners, who provide core funding to WRI: Netherlands Ministry of Foreign Affairs, Royal Danish Ministry of Foreign Affairs, and Swedish International Development Cooperation Agency.

This issue brief was supported by a project that is part of the International Climate Initiative (IKI). The Federal Ministry for the Environment, Nature Conservation and Nuclear Safety (BMU) supports this initiative on the basis of a decision adopted by the German Bundestag.

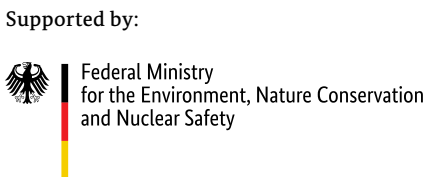

The authors would like to thank the external reviewers of this publicationAnkit Bhardwaj, Kent Buchanan, Robbie Orvis, and Eduardo Sanchez Sierrafor their comments and suggestions, which have greatly improved this issue brief. Thank you also to WRI colleagues Natalie Elwell, Karl Hausker, Kelly Levin, Tirthankar Mandal, Emily Mangan, David Rich, Laura Malaguzzi Valeri, Michael Westphal, and Arief Wijaya for their helpful reviews.

\section{ABOUT THE AUTHORS}

Roman Hennig is a former Research Analyst at WRI's Climate Program.

Juan-Carlos Altamirano is a Senior Economist at WRI's Economics Center and Climate Program.

Contact: JCAltamirano@wri.org

\section{PHOTO CREDITS}

Cover, p. 2: Karsten Wurth. 


\section{ABOUT WRI}

World Resources Institute is a global research organization that turns big ideas into action at the nexus of environment, economic opportunity and human well-being.

\section{Our Challenge}

Natural resources are at the foundation of economic opportunity and human well-being. But today, we are depleting Earth's resources at rates that are not sustainable, endangering economies and people's lives. People depend on clean water, fertile land, healthy forests, and a stable climate. Livable cities and clean energy are essential for a sustainable planet. We must address these urgent, global challenges this decade.

\section{Our Vision}

We envision an equitable and prosperous planet driven by the wise management of natural resources. We aspire to create a world where the actions of government, business, and communities combine to eliminate poverty and sustain the natural environment for all people.

\section{Our Approach}

COUNT IT

We start with data. We conduct independent research and draw on the latest technology to develop new insights and recommendations. Our rigorous analysis identifies risks, unveils opportunities, and informs smart strategies. We focus our efforts on influential and emerging economies where the future of sustainability will be determined.

\section{CHANGE IT}

We use our research to influence government policies, business strategies, and civil society action. We test projects with communities, companies, and government agencies to build a strong evidence base. Then, we work with partners to deliver change on the ground that alleviates poverty and strengthens society. We hold ourselves accountable to ensure our outcomes will be bold and enduring.

\section{SCALE IT}

We don't think small. Once tested, we work with partners to adopt and expand our efforts regionally and globally. We engage with decision-makers to carry out our ideas and elevate our impact. We measure success through government and business actions that improve people's lives and sustain a healthy environment.

Each World Resources Institute issue brief represents a timely, scholarly treatment of a subject of public concern. WRI takes responsibility for choosing the study topics and guaranteeing its authors and researchers freedom of inquiry. It also solicits and responds to the guidance of advisory panels and expert reviewers. Unless otherwise stated, however, all the interpretation and findings set forth in WRI publications are those of the authors.

Cccreative commons (P) Copyright 2020 World Resources Institute. This work is licensed under the Creative Commons Attribution 4.0 International License. 
WORLD

RESOURCES

I NST I T U T E

$10 \mathrm{G}$ STREET NE

SUITE 800

WASHINGTON, DC 20002, USA

+1 (202) 729-7600

WWW.WRI.ORG 